\title{
Discourse update at the service of mirativity effects: The case of the Discursive Dative*
}

\author{
Elitzur Bar-Asher Siegal \\ Hebrew University of Jerusalem
}

\author{
Nora Boneh \\ Hebrew University of Jerusalem
}

\begin{abstract}
The classic model of conversation based on the Common Ground (CG), introduced by Karttunen (1974), Lewis (1979) and Stalnaker (1978), was shown to be insufficient for accounting for various conversational phenomena (inter alia Portner 2004, 2007; Farkas \& Bruce 2009; Murray 2014). This paper further strengthens this line by analyzing a type of non-truth conditional non-core dative termed the Discursive Dative (DD) as a discourse management device (Krifka 2008; Repp 2013). The DD signals that the asserted proposition $p$ constitutes an exception to a normative generalization believed by the speaker to be shared by the speech event participants. In order to capture the notion of exception we propose to divide the CG into two sets of worlds, those consistent with previous assertions and their presuppositions $\left(\mathrm{CG}_{\mathrm{A}}\right)$ and those consistent with generalizations $\left(\mathrm{CG}_{\mathrm{G}}\right)$. The $\mathrm{DD}$ signals a non-inclusion relation between the asserted proposition and the $\mathrm{CG}_{\mathrm{G}}$. This enables us to distinguish between different types of mirativity effects, by drawing a distinction between adding a proposition $p$ that was not previously in the speaker's expectation-set (inter alia DeLancey 1997, 2001; Rett 2009; Peterson 2013; Rett \& Murray 2013) and the present case of the DD, where $p$ can very well be in the speaker's expectation-set, but objectively expected that $\sim p$.
\end{abstract}

Keywords: Common Ground, discourse update, exception, mirativity, non-core dative

\section{Introduction}

The paper aims at providing further support for the claim that having a model with only the classic Common Ground (CG) introduced by Karttunen (1974), Lewis (1979) and Stalnaker (1978) is insufficient for accounting for various conversational phenomena (other reasons for making such a claim were provided by inter alia Portner 2004, 2007; Farkas \& Bruce 2009; Murray 2014). The

\footnotetext{
* Thanks to Edit Doron, Yael Greenberg, Aynat Rubinstein and to the reviewers and audiences of SALT26, IATL31 and TbiLLC2015 for valuable feedback. The paper is supported by an ISF grant \#1366/14 to Nora Boneh.
} 
Discourse update at the service of mirativity effects: The case of the Discursive Dative

empirical motivation for the current proposal comes from an examination of a phenomenon in Hebrew of a construction containing a non-truth conditional noncore dative, termed by Bar-Asher Siegal \& Boneh (2015a) the Discursive Dative (DD):

$$
\begin{aligned}
& \text { hu lo lakax liod 'et ha-trufa! } \\
& \text { he not took to.me ACC the-medicine } \\
& \text { 'He didn't take his medicine. That's weird!' }
\end{aligned}
$$

The dative component is a PP consisting of the preposition $l$ - 'to', and its object. ${ }^{1}$

We claim that its use in (1) relies on the knowledge that the relevant person is following a medical treatment, and the deontic generalization that in the relevant case people follow the norm and take the medicine prescribed to them. Thus, the fact expressed in (1) is an exception to this deontic generalization, while the generalization itself still holds true. We will suggest, accordingly, that the DD is a discourse management device. As such, its role is to indicate the status of $p$ against the background of the conversation (cf. Krifka 2008; Repp 2013; Murray 2014). In other words, in what follows, we will analyze the DD as a linguistic expression which points to the fact that the asserted proposition constitutes an EXCEPTION to a generalization assumed by the speaker to be available to the speech event participants.

Providing a discourse update analysis for the DD construction explains a hitherto unresolved issue pertaining to this type of non-core dative construction. Previous studies of non-core datives in Hebrew (Berman 1982; Borer \& Grodzinsky 1986; Ariel et al. 2015) characterize what we call the DD as part of the broader phenomenon of Ethical Dative (ED), whose function is to express the speaker's stance towards the underlying proposition, usually the speaker's surprise or irritation concerning the content of the proposition (cf. Juitteau \& Rezac 2007 for French; Gutzmann 2007 for German; Rákosi 2008 for Hungarian; Michelioudakis \& Kapogianni 2013 for Modern Greek, among many others for related constructions in various languages). In contrast to this view, we will argue that the DD is not primarily dedicated to the expression of surprise or other such emotional stances. Consequently, we will propose a new type of mirativity effect.

Our account for grasping the semantics of the DD traces the source of this undocumented mirativity effect to a particular discourse update where the state of affairs denoted by the prejacent is not compatible with a set of backgrounded objective norms, and therefore is expected not to occur. This contrasts with previous accounts of similar such effects (see inter alia DeLancey 1997, 2001;

\footnotetext{
${ }^{1}$ By dative, we follow a common practice in the literature to refer to whichever form a given language uses to express dative case, or the equivalent of the dative case in languages with no morphological case. In Hebrew the form is $l$-DPs 'to-DP'. In all the examples the relevant dative pronoun is marked with the subscript DD.
} 
Discourse update at the service of mirativity effects: The case of the Discursive Dative

Rett 2009; Peterson 2013; Rett \& Murray 2013), which rely on the analysis that the state of affairs denoted by the prejacent is not part of a contextually available set of the speaker's personal expectations, and therefore not expected to occur.

The paper is organized as follows. In the next section, we present the DD and discuss the interpretative properties of constructions containing it; in Section 3, we carefully tease apart the conversational effects induced by the DD from its main interpretative contribution described in Section 2. Section 4 details our analysis of the DD modelling the notion of EXCEPTION. In Section 5 we provide substantiation for the proposed analysis. Section 6 concludes.

\section{The Discursive Dative}

Colloquial Hebrew has a construction featuring a non-selected non-core dative in the first and second person. We will begin with a description of this construction putting an emphasis on its interpretative properties. Consider the following documented example in the context provided:

$$
\begin{aligned}
& \text { [(B) is singing, his wife (A) says]: }{ }^{2} \\
& \text { A: ze ha-tav še-'ani haxi sonet! } \\
& \text { this the-musical note that-I the.most hate.FSG } \\
& \text { 'This is the musical note I hate most!' } \\
& \text { B: ma 'at sonet lid tavim?! } \\
& \text { what you.FSG hate.FSG to.me musical notes } \\
& \text { 'How come you hate musical notes?!' }
\end{aligned}
$$

B's utterance expresses the following meaning components: (i) The speaker (B) didn't know until now that his wife (A) hated particular musical notes; (ii) the generalization that people do not hate musical notes. The DD $l i$ 'to me' has no truth conditional contribution to the meaning of the proposition, and therefore it could be omitted from the English translation. Further evidence for the irrelevance of the DD to truth conditions will be provided in Section 5. Crucially then, the sentence with a DD makes salient a conversational background, detailed in (ii) for the current example.

What attests to there being a salient generalization in the conversational background is an exchange like the following, that could naturally continue the one in (2):

\footnotetext{
${ }^{2}$ This is an attested example, N. Faust (p.c)
} 
Discourse update at the service of mirativity effects: The case of the Discursive Dative
A: lama 'ata omer 'et ze? why you say ACC this 'Why do you say so?'
B: 'anašim lo son'im tavim people not hate.PL musical notes 'People don't hate musical notes.'

Here, when the wife, A, asks for B to clarify the purpose of his utterance, he does so by making explicit the generalization he takes to hold in the conversational background.

Additional attested examples further illustrate the point that the clause containing a DD makes available a salient generalization. As the following documented examples show, either the generalization is made explicit in the speaker's utterance (4) or they can be accommodated contextually (5). Example (4) is a reaction by the speaker to the information that his acquaintance is preparing to fly to Switzerland to watch a soccer game.

$$
\begin{aligned}
& \text { 'eyze tas la-misxak? be-'aškelon hu lo holex, } \\
& \text { which fly to.the-game, in-Ashkelon he not go, } \\
& \text { ex tas liob le-švaic?! } \\
& \text { how flying to.me to-Switzerland }
\end{aligned}
$$

'What do you mean fly to the (soccer) game, this is unusual since even to Ashkelon he won't go, now he's flying to Switzerland?!'

The statement in (4) 'ex tas li le-švaic 'how come he's flying to Switzerland', relies on the knowledge that the relevant person never goes to soccer games as he never even goes to watch local games (Ashkelon is a town in Israel). It relies on the epistemic generalization that whoever is not interested in going to local soccer games would not travel abroad to watch them. Consider next (5):

$$
\begin{array}{llllll}
\text { 'axšav, 'al kol falcan } & \text { hem } & \text { yešalmu } & \text { lipD } & \text { milyon yuro } \\
\text { now, on every } & \text { stuck up } & \text { they } & \text { will.pay } & \text { to.me } & \text { million euro }
\end{array}
$$

'Now, they'll be willing to pay a million euros for every stuck up (soccer player).'

The speaker in (5) presents his conjectures as to the sums of money involved in the acquisition of soccer players. The statement in (5) relies on the moral generalization, to which the speaker adheres, that one should not pay such big sums for just any soccer player.

For both cases, it is significant that the fact signaled by the prejacent, namely, the dative-less proposition (his flying to the game in Switzerland (4), and their eventual paying of a million euros for just any soccer player (5)) does not alter the generalization explicitly stated in (4) as: be-'aškelon hu lo holex 'even to 
Discourse update at the service of mirativity effects: The case of the Discursive Dative

Ashkelon he won't go', and accommodated in the case of (5). Crucially, as will be elaborated in Section 4, these generalizations are not factual universal claims which presumably cannot allow exceptions. They are norms and therefore it is possible to encounter events that do not follow the generalizations that constitute the relevant norms. Here lies the source for our claim that the datival expression marks the assertion as an exception to a salient contextual generalization.

\section{The mirativity effect induced by the DD}

The examples containing DDs described in the previous section all pertain to a colloquial register and are highly expressive. Similar sentences to those we group in Hebrew under the category of DD were previously analyzed as tokens of what is often designated in the literature as Ethical Datives (ED). ${ }^{3}$ The ED is characterized as holding the following two properties: first, it is restricted to first and/or second person; second, it expresses the speaker's emotional stance towards the underlying proposition, often irritation or surprise. ${ }^{4}$ In other words, the ED gives rise to a mirativity effect (cf. Rooryck 2001). The goal of this section is to demonstrate, at least for the DD in Hebrew, that while this type of datival construction is indeed restricted to first and second person, singular and plural, the DD should not be categorially classified as a mirativity marker, whose main semantic contribution is to convey an emotional stance of the speaker (cf. DeLancey 1997; Peterson 2013). Accordingly, these effects are merely by products of the main function of the DD.

First and foremost, it is crucial to point out that the effect of surprise is in fact epiphenomenal. Examples (6)-(8) clearly show that the DD by itself does not encode surprise or expectations, since while uttering the assertions in (1), (4)-(5) above the speaker may very well comment on the expectedness of the asserted propositions.

$$
\begin{aligned}
& \text { 'at 'od tisne'i lid tavim } \\
& \text { you more will hate to.me musical notes } \\
& \text { '(At the end) you may even get to hate musical notes.' }
\end{aligned}
$$

\footnotetext{
${ }^{3}$ This paper is part of a broader project, outlined in Bar-Asher Siegal and Boneh (2015a), of classifying non-core datives in Hebrew and in other languages. In this typology the main criterion for the classification of these datives has to do with the contribution of the dative to the truthconditions. Accordingly, there are no justifications for having the ED as an independent category. Sentences which were previously analyzed as examples of ED, in the current classification, fall under two different categories, depending on whether the datival expression contributes to the truth-conditions of the sentence in which it appears.

${ }^{4}$ For a more extensive discussion of the Ethical Dative see Bar-Asher Siegal \& Boneh (2015a) and references therein.
} 
Discourse update at the service of mirativity effects: The case of the Discursive Dative

ze lo mafti'a 'oti še-lamrot še-be-'aškelon hu lo holex,
it not surprise me that-although that-in-Ashkelon he not go,
hu tas lipd le-švaic
he flying to.me to-Switzerland

'It doesn't surprise me that although he won't go to Ashkelon, he's flying to Switzerland.'

\begin{tabular}{|c|c|}
\hline $\begin{array}{l}\text { barur/cafuy } \\
\text { clear/expected }\end{array}$ & $\begin{array}{l}\text { še-'axšav } \\
\text { that-now }\end{array}$ \\
\hline $\begin{array}{ll}\text { n } & \text { yešalmu } \\
\text { y } & \text { will.pay }\end{array}$ & $\begin{array}{ll}\text { lidD } & \text { milyon } \\
\text { to.me } & \text { millior }\end{array}$ \\
\hline
\end{tabular}

'It is clear/expected that now for every stuck up soccer player they'll be willing to pay a million euros.'

In (6) the speaker predicts that "you will come to hate musical notes" namely that this state of affairs is expected by the speaker to stand in contrast to the available generalization in the background "people do not hate musical notes". Similarly, in (7)-(8), one can see that the asserted proposition including the DD can be embedded under the predicates such as 'be surprised', 'be clear', 'be expected'. In other words, we discard the possibility that the DD in Hebrew is a mirativity morpheme dedicated to the expression of surprise or that it implies that subjectively the statement was unexpected by the speaker. Instead, we develop in the next section the notion of EXCEPTION, where a proposition may have an objective status of 'expected to not be true' due to certain accepted norms with which that proposition is inconsistent. To be more specific, for Rett (2011) and Rett \& Murray (2013), the addition of a mirative expression to a proposition $p$ conveys that $p$ was not previously in the speaker's expectation-set. In our case, $p$ can still be in the speaker's expectation-set. It is only crucial that, from a normative point of view, it was expected that $\sim p$.

We turn now to the emotional stance produced in these constructions. Again, it can be shown that this is not a core meaning component of the DD since it can be overridden. This is illustrated in the following examples, where it is perfectly possible to add expressions such as "... but I don't care/give a damn" to all the above examples. ${ }^{5}$ For instance:

${ }^{5}$ Crucially, such expressions cannot be felicitously added to constructions who truly express an emotional or psychological effect, namely Affected Dative (AD) constructions (see Bar-Asher Siegal \& Boneh 2015a, cf. Bosse et al. 2012). In (i) the dative has an entirely different purpose, which is adding an affected participant:

(i) a. 'axarkax hu tas li le le-šana la-mizrax, ve-hiš'ir 'oti xareda ve-lexuca Then he flew to.me to-year to.the-east, and-left me anxious and-stressed 'The he flew on me to the Far East for a year, and left me anxious and stressed.' 
Discourse update at the service of mirativity effects: The case of the Discursive Dative

ze lo maziz li še-'at sonet lidD tavim, it not move.SG to.me that you.F hate to.me musical notes 'I don't care that you hate some musical notes.'

a. 'eyze tas la-misxak? be-'aškelon hu lo holex, which fly to.the-game? in-Ashkelon he not go,

ex tas lidp le-švaic?!

how flying to.me to-Switzerland

'What do you mean fly to the (soccer) game, this is unusual since even to Ashkelon he won't go, he's flying to Switzerland?!

b. ...'aval 'ani ma 'expat li
...but I

'...but what do I care?'

To sum up, the fact that the connotations of irritation, surprise or other such attitudes, often related to this type of non-core dative, are cancellable reveals that they are by-products of its essential property, which is to draw attention to a particular relationship of incompatibility between the expressed dative-less proposition and a background generalization (cf. Ariel et al. 2015).

\section{Analysis: Modeling the notion of EXCEPTION}

To model the notion of EXCEPTION essential for the understanding the function of the DD, we begin by following the basic lines of the model of conversation endorsed by Karttunen (1974), Lewis (1979) and Stalnaker (1978). According to this model, assertions stand against a set of world-states that constitute the background knowledge shared by the conversational participants and rule out certain possible world-states as not obtaining. A successful assertion ends with a new proposition admitted into the shared background knowledge. Assertions,

\begin{tabular}{lllll}
\hline b. \# & 'aval ma 'expat li \\
& but what care & to.me \\
& but what do I care.'
\end{tabular}

In this attested example, where the datival expression is added to the same type of predicate as in (4) above, the referent of the dative is emotionally affected by his flying to the Far East, as the second part of the example makes clear ("and left me anxious and stressed"). In such cases, adding lo ixpat li 'I don't care' results in an incoherent discourse, since the speaker is clearly psychologically affected, and this affect cannot be cancelled. Note that in this example there is no salient normative generalization, epistemic or deontic, in the conversational background. In other words, we point to a correlation between the possibility to cancel the emotional or psychological effect or the speaker's stance and the availability of a relevant normative generalization in the conversational background. We have shown that in the case of the DD, where such generalizations are available, the emotional stance is always cancellable. 
Discourse update at the service of mirativity effects: The case of the Discursive Dative

accordingly, narrow the set of world-states ('the context set') that remain compatible with what has been presupposed or established. This set of worldstates is the way to formally represent the Common Ground (CG), the shared information mutually recognized by the speech event participants.

Numerous studies have shown that this model is insufficient for tackling various conversational phenomena (see inter alia Portner 2004, 2007; Farkas \& Bruce 2009; Murray 2014). Farkas and Bruce (2009), for example, argue that in order to grasp the function of polar questions one must emphasize the proposal nature of assertion. Accordingly, they characterize ordinary assertions as proposing additions to the $\mathrm{CG}$, rather than actually changing it.

We would like to add another component to this model of the CG, an addition that stems from the recognition that an assertion can come with a discourse management device. The notion of a discourse management device was introduced by Krifka (2008) for linguistic expressions that indicate the CG status of a proposition. Repp (2013), following Romero \& Han (2004), proposes various discourse management devices, indicating whether or not a proposition $p$ is part of the CG or indicating the interlocutors' current stance towards $p$. In what follows we will propose to consider a new type of discourse management device for capturing the notion of EXCEPTION. In order to model it we have to make some amendments to the classic model of the conversation concerning the structure of the context set.

The notion of EXCEPTION challenges the classic model of CG dealing only assertions and presupposition, which are sets of possible worlds that are either part of the CG or not. The reason for this challenge stems from the fact that it requires a mechanism that allows certain propositions to have a double status: on the one hand, to be asserted as true, and on the other hand, to be set of worlds that are not a sub-set of the set of worlds that constitute those of the background accepted assumptions. Thus, while a proposition $p$ is asserted, there is a generalization accepted by the speech event participants that entails that $\sim p$, which all of the participants in the conversation do not reject despite the acceptance of $p$ as true. Thus, conversations also rely on the acceptance of various modal (epistemic, stereotypical, and deontic) generalizations (cf. Portner 2007). These generalizations allow prospects as to which possible worlds should obtain. Thus, we propose to divide the representation of the CG into two sets of worlds, those consistent with previous assertions and their presuppositions $\left(\mathrm{CG}_{\mathrm{A}}\right)$ and those consistent with generalizations $\left(\mathrm{CG}_{\mathrm{G}}\right)$. (11) characterizes the addition to the CG we would like to propose:

(11) The $\mathrm{CG}_{\mathrm{G}}$ is a set, which contains possible worlds that are consistent with various generalizations, without exceptions. 
Discourse update at the service of mirativity effects: The case of the Discursive Dative

The generalizations relevant for the phenomenon of the DD are normative from the perspective of the speaker, in the broader sense of the term, encompassing what is considered to be the normal or the appropriate way of doing something or what normally happens. Thus, the nature of such generalizations can be either deontic or stereotypical; for example, the generalization, against which the prejacent of (1) is made, is deontic. In other words, the $\mathrm{CG}_{\mathrm{A}}$ is a set of worlds consistent with statements, assumed or asserted in the conversation; while the $\mathrm{CG}_{\mathrm{G}}$ is a set of worlds consistent with the normative statements assumed in the conversation. Consequently, these generalizations should be modelled as all the speaker's epistemically accessible worlds $w^{\prime}$ that conform to the speaker's knowledge in $w$, and assumed by him to be part of the common knowledge of all given interlocutors, about what is the normative state-of-affairs.

Such generalizations are related to generics (characterizing sentences) if those are analyzed as modals, expressing normativity, and as such containing universal quantifiers over possible worlds (inter alia Asher \& Morreau 1995). These general statements must be different from generics if the latter are defined as a certain type of assertions about the actual world, in such a way as to allow for exceptions, since as such they are part of the $\mathrm{CG}_{\mathrm{A}}$ (cf. Krifka et al. 1995; Cohen 2004; Greenberg 2007 inter alia).

Consequently, we suggest the following semantic representation for the DD as a discourse management device, capturing the notion of exception:

$[[\mathrm{DD}]]^{s p}=\lambda p<\mathrm{s, \textrm {t }}>\lambda w \forall w^{\prime} \in \mathrm{Epi}_{s p}(w)\left(p \not \subset \mathrm{CG}_{\mathrm{G}} w^{\prime}\right) \cdot p(w)$

In all the speaker's epistemically accessible worlds $w^{\prime}$ that conform to the speaker's knowledge in $w$ (and assumed by him to be part of the common knowledge), it holds that the proposition in question is not in the $C G_{G}$.

Discourse management devices only indicate the status of $p$ in the CG. As such the $[[\mathrm{DD}]]^{s p}$ takes a proposition with its truth value and never alters it (see also Section 5); the only new contribution of the DD is an additional indication about the status of the proposition with respect to the $\mathrm{CG}_{\mathrm{G}}$, namely that this set of worlds does not intersect with $\mathrm{CG}_{\mathrm{G}}$. Thus, the part in the formula before the period "." only indicates felicity and not a truth-conditional meaning. ${ }^{6}$

Once our model divides the context set into two sets of worlds, those consistent with previous assertions and their presuppositions $\left(\mathrm{CG}_{\mathrm{A}}\right)$ and those consistent with the relevant generalizations $\left(\mathrm{CG}_{\mathrm{G}}\right)$, we can think of various logical relations between the two sets of worlds, and it is our claim that this is precisely

\footnotetext{
${ }^{6}$ The formula in (12) is suited only for indicative statements, in which $p$ is evaluated according to the actual world. This is, however, not necessary. As examples (5) and (6) demonstrate, the DD can be added to modal statements as well. This further development is beyond the scope of the current paper.
} 


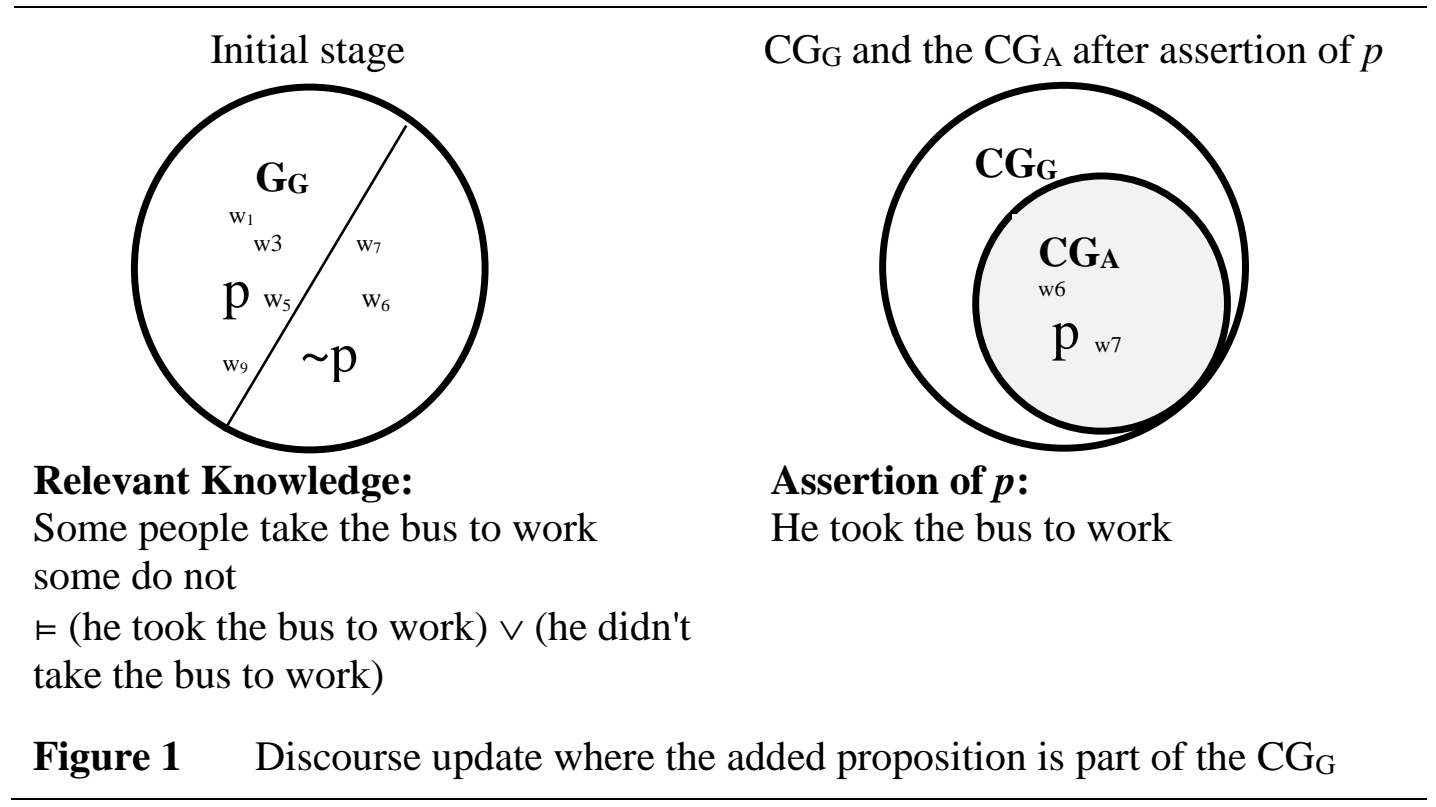

what is relevant for the linguistic phenomenon of DD, and more specifically to the felicity of its use. According to (12), what felicitates the appearance of the DD is the fact that the $\mathrm{CG}_{\mathrm{G}}$ and the set of worlds in which $p$ is true are disjoint. Therefore it is possible to add the DD to $p$ when $\sim p$ is entailed by $\mathrm{CG}_{\mathrm{G}}$, as summarized in (13).

(13) The DD is a discourse management device indicating the non-overlap between the $\mathrm{CG}_{\mathrm{A}}$ and the $\mathrm{CG}_{\mathrm{G}}$.

We turn now to illustrate the relevance of the various logical relations between the $\mathrm{CG}_{\mathrm{G}}$ and the $\mathrm{CG}_{\mathrm{A}}$. The $\mathrm{CG}_{\mathrm{A}}$, as a set of worlds, can be a subset of the $\mathrm{CG}_{\mathrm{G}}$, with respect to a relevant proposition. From a discursive point of view, no need arises to assert sentences that are true in the $\mathrm{CG}_{\mathrm{G}}$, for example, when it is a valid conversational assumption to assume the knowledge that "The sun rises in the east". It goes without saying that in such a case a DD would be infelicitous, and may only be appropriate in a science fiction scenario, where the course of plants may be altered, in which case the $\mathrm{CG}$ will be a different one.

Now, when the $\mathrm{CG}_{\mathrm{A}}$ is a subset of the $\mathrm{CG}_{\mathrm{G}}$, sentences that are held true in all possible worlds members of the $\mathrm{CG}_{\mathrm{A}}$ and in some of the worlds that are members of the set of the $\mathrm{CG}_{\mathrm{G}}$ (i.e. it is not inconsistent with any generalization) are infelicitous with a DD. This is illustrated in (14) and schematized in Figure 1.

$$
\begin{array}{llll}
\text { hu nasa } & \text { \#li } & \text { la-'avoda } & \text { ba-'otobus } \\
\text { He drove } & \text { to.me } & \text { to.the-work } & \text { in.the-bus }
\end{array}
$$

'He went to work by bus. \#That's weird!' 


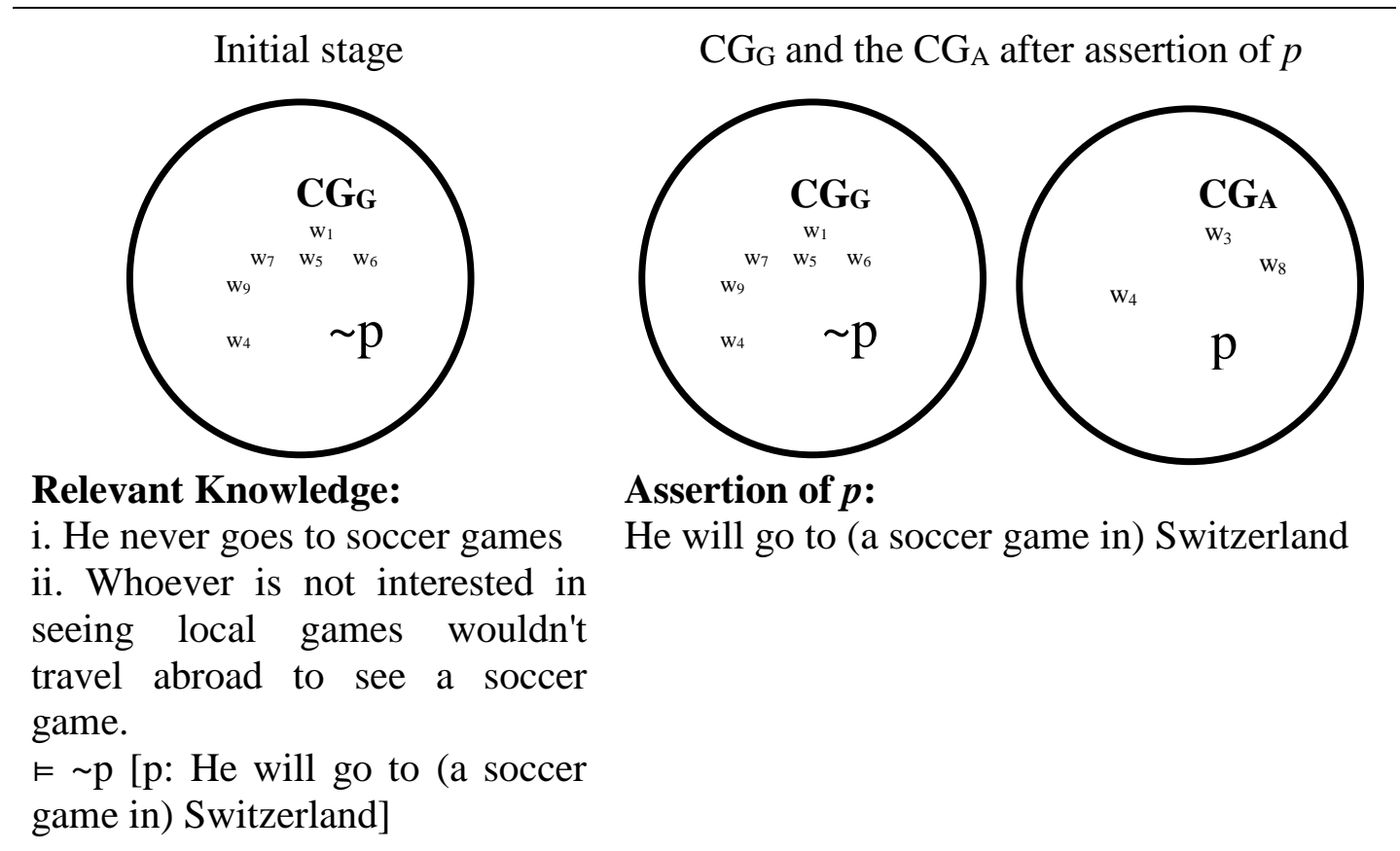

Figure 2 Discourse update where the added proposition is not part of the $\mathrm{CG}_{\mathrm{G}}$

In Figure 2, we schematize the case where the $\mathrm{CG}_{\mathrm{G}}$ and the $\mathrm{CG}_{\mathrm{A}}$ are disjoint. The $\mathrm{CG}_{\mathrm{G}}$ is the set of all possible worlds which do not obtain $p$, since an accepted generalization entails that $p$ does not hold. Thus, the $\mathrm{CG}_{\mathrm{A}}$, which contains only the possible worlds in which $p$ hold, and the $\mathrm{CG}_{\mathrm{G}}$ are disjoint.

'eyze tas la-misxak? be-'aškelon hu lo holex, Which fly to.the-game? in-Ashkelon he not go,

ex tas li DD $_{\text {le-švaic?! }}$

how flying to.me to-Switzerland

'What do you mean fly to the (soccer) game, this is unusual since even to Ashkelon he won't go, how come he's flying to Switzerland?!'

$\mathbf{C G}_{\mathbf{A}} \mathrm{He}$ is flying to Switzerland (for a soccer game)

CGg Given his habits, he does not fly abroad (for soccer games)

$\vDash$ He isn't flying to Switzerland (for a soccer game)

$\mathrm{CG}_{\mathrm{A}} \not \subset \mathrm{CG}_{\mathrm{G}} \rightarrow \mathrm{DD}$ is felicitous

In the remainder of this section, we return to the examples with the DD (1)(2), (5) and schematically illustrate the relation between the $\mathrm{CG}_{\mathrm{G}}$ and the $\mathrm{CG}_{\mathrm{A}}$ for each. In what follows, norms are stated as generic ("People do $\mathrm{X}$ in the case of $Y^{\prime \prime}$ ) and not as modals ("People should do $\mathrm{X}$ in the case of $\mathrm{Y}^{\prime \prime}$ ), as we wish to capture the set of worlds in which the generalizations are realized. 
Discourse update at the service of mirativity effects: The case of the Discursive Dative

(16) hu lo lakax lipd 'et ha-trufa! he not took to.me ACC the-medicine 'He didn't take his medicine. That's weird!'

$\mathbf{C G}_{\mathbf{A}}$ He did not take the medicine (prescribed to him)

CGg People who are ill take the medicines prescribed to them $\vDash$ He took the medicine prescribed to him $\mathrm{CG}_{\mathrm{A}} \not \subset \mathrm{CG}_{\mathrm{G}} \rightarrow \mathrm{DD}$ is felicitous

ma 'at sonet li $\mathbf{D}_{\mathrm{DD}}$ tavim?!

what you.FSG hate.FSG to.me musical notes

'How come you hate notes?!'

$\mathbf{C G}_{\mathbf{A}}$ You hate some musical notes

CG Musical notes are not something people usually hate $\vDash$ You don't hate musical notes

$\mathrm{CG}_{\mathrm{A}} \not \subset \mathrm{CG}_{\mathrm{G}} \rightarrow \mathrm{DD}$ is felicitous

'axšav 'al kol falcan 'od yešalmu li now on every stuck up more will pay to.me million euro 'Now for every stuck up (player) they will pay a million euro.'

$\mathbf{C G}_{\mathbf{A}}$ They will pay a million euros for every stuck up player

CGG No one pays large amounts of money for just any player $\vDash$ They will not pay a million euros for every stuck up player $\mathrm{CG}_{\mathrm{A}} \not \subset \mathrm{CG}_{\mathrm{G}} \rightarrow \mathrm{DD}$ is felicitous

Finally, as is clear from our definition, what is crucial for the DD in order to be felicitous is that the $\mathrm{CG}_{\mathrm{A}}$ and the $\mathrm{CG}_{\mathrm{G}}$ are disjoint. Accordingly, it is only crucial that $p$ is inconsistent with one of the generalization that are part of $\mathrm{CG}_{\mathrm{G}}$. The following example, relating to Isaac's Binding from the book of Genesis, illustrates that this inconsistency can result from a proposition different from $p$, but still entailed by $p$ :
'avraham kima't šaxat
li DD 'et ha-ben šelo
Avraham almost slaughtered to.me ACC the-son his
'Abraham almost slaughtered his son!'
$\mathbf{C G}_{\mathbf{A}}$ Abraham almost slaughtered his son
$\vDash$ Abraham thought of slaughtering his son
CGG Fathers do not slaughter their sons
$\vDash$ Abraham didn't think of slaughtering his son
$\mathrm{CG}_{\mathrm{A}} \not \subset \mathrm{CG}_{\mathbf{G}} \rightarrow \mathrm{DD}$ is felicitous

In this example, the generalization by itself seems to only infer that fathers do not slaughter their sons, but prima facie not that "they do not almost slaughter their sons". As illustrated above, the inconsistency derives from a plausible entailment from the sentence in (19), which is that Abraham had in mind to slaughter his son. 
Discourse update at the service of mirativity effects: The case of the Discursive Dative

At the same time there is a plausible entailment from the norm "fathers do not slaughter their sons" that they do not even entertain the thought of doing so. The inconsistency stems, therefore, from the entailments of the asserted $p$ and of the deontic generalization in the $\mathrm{CG}_{\mathrm{G}}$.

In the following section, we turn to present some evidence in support for our analysis.

\section{Substantiation}

First and most importantly, DDs do not affect truth conditions. According to (12), the DD never alters the truth value of the proposition to which it is added, it only indicates the CG status of that proposition. The following observation is a major piece of evidence for this claim (see Bar-Asher Siegal \& Boneh 2015a, for a fuller discussion):

hu lo lakax lido/lexado/lanud 'et ha-trufa!
he not took to.me/to.you/to.us ACC the-medicine
'He didn't take his medicine. That's weird!'
'eyze tas la-misxak? be-'aškelon hu lo holex,
which fly to.the-game? in-Ashkelon he not go,
ex tas liod/lexado/lanud le-švaic?!
how flying to.me/to.you/to.us to-Switzerland

'What do you mean fly to the (soccer) game, this is unusual since even to Ashkelon he won't go, he's flying to Switzerland?!'

These examples show that the referent of the DD can be either of the speech event participants. There is no truth conditional effect dependent on this choice. In this respect the DD radically differs from other non-core datives in Hebrew, where a change in referent induces a change in the denotation of the affected additional event participant, be it e.g. a beneficiary, maleficiary or an affected experiencer (Bar-Asher Siegal \& Boneh, 2015a, see also fn. 5 above).

Second, the DD operates on a proposition. Being a discourse management device, the DD always scopes above negation. Since the DD indicates the relationship between the $\mathrm{CG}_{\mathrm{G}}$ and the $\mathrm{CG}_{\mathrm{A}}$, it may do so only after the $\mathrm{CG}_{\mathrm{A}}$ is already updated. This is relevant only after the truth conditions of the entire proposition are computed, and for this purpose negation is part of the proposition, and as such it is evaluated with respect to the $\mathrm{CG}_{\mathrm{G}}$. This is precisely the case in example (1)/(16). Consider its affirmative version in (22): 
Discourse update at the service of mirativity effects: The case of the Discursive Dative

(22) hu lakax lipd 'et ha-trufa

he took to.me ACC the-medicine

'He took his medicine. That's weird!'

$\mathbf{C G}_{\mathbf{A}}$ He took his medicine

CGG People who are healthy do not take medicines

$\vDash$ He did not take medicines if he is healthy

$\mathrm{CG}_{\mathrm{A}} \not \subset \mathrm{CG}_{\mathrm{G}} \rightarrow \mathrm{DD}$ is felicitous

The use of the DD in this case is felicitous in a context where the generalization is that he should not take his medicine, if e.g. he finished his dosage, or is allergic to its ingredients. This observation regarding the scopal interaction of negation is not a trivial one. As Bar-Asher Siegal \& Boneh (2015a) note, other types of non-core datives can scope below negation as well. In particular, in the case of the Affected Dative the datival expression can be part of the negated event or attach above it, enabling two types of readings: being affected by the non-occurrence of the event, or negating that there was an affecting event. In other words, the prejacent to which a DD is added is of the opposite polarity to that of the proposition on which the normative generalization in the conversational background is based. Here is an additional example, based on (4)/(15) above:
hu lo tas lidp le-švaic
He not flew to.me to-Switzerland
'He didn't fly to Switzerland. That's weird!'

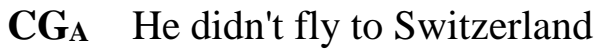
CGg Given his habits, he flies abroad
$\vDash$ He flies to Switzerland
$\mathrm{CG}_{\mathrm{A}} \not \subset \mathrm{CG}_{\mathrm{G}} \rightarrow \mathrm{DD}$ is felicitous

Further substantiation for our analysis of the DD as a discourse management device comes from the possible clause types allowed for clauses featuring the DD. First, being a discourse management device the DD is not expected to occur in embedded clauses. The reason is that the embedded proposition is not the one directly up for being added to the CG. The following example attests that this is indeed case.

dani yada še-hu lo lakax \#li Dani knew that-he not took to.me/you/us ACC the-medicine 'Dani knew that he didn't take his medicine, (\#which is weird).'

Note however that this state of affairs obtains when the attitude holder is not a speech event participant. In comparison, in (7)-(9) above, a DD in the embedded 
Discourse update at the service of mirativity effects: The case of the Discursive Dative

clause poses no problem, when the explicit or implicit epistemic argument of the main predicate is the speaker.

Second, the DD is not felicitous in polar interrogatives clauses.

$\begin{array}{lllll}\text { \#hu lakax } & \mathbf{l i}_{\mathrm{DD}} / \mathbf{l e x a} \mathbf{D D}_{\mathrm{DD}} / \mathbf{l a n u}_{\mathrm{DD}} & \text { 'et } & \text { ha-trufa? } \\ \text { he } & \text { took } & \text { to.me } & \mathrm{ACC} & \text { the-medicine }\end{array}$

'Did he take his medicine?' (Intended: contrary to what a person like him should do in a similar situation)

Interrogatives with DDs can only be felicitous as rhetorical questions. These two facts are of no surprise if we assume the analysis of Hamblin (1973)/Karttunen (1977) for questions (26), according to which the semantics of a question is the set of propositions that correspond to a possible answer to the question.

$$
[[\mathrm{Q}]]=\lambda p_{<\mathrm{s}, \mathrm{t}}>\lambda w_{\mathrm{s}} \lambda q<\mathrm{s}, \mathrm{t}>[\mathrm{q}=\mathrm{p} \vee \mathrm{q}=\sim \mathrm{p}]
$$

Accordingly, it is impossible to add the DD to a question since it contains both $p$ and $\sim p$, and only one of them is inconsistent with the contextual norm. Therefore, the felicity condition specified in $(12) /(13)$ is not met. However, when the question is rhetorical it is possible to add the DD. For our purposes, it is sufficient to say that in the case of rhetorical questions the semantics of the question is not the set of propositions that correspond to a possible answer to the question, but merely one answer, salient in the context. In fact it is possible to raise a rhetorical question only when the answer is given to both interlocutors, and therefore this answer is added to the $\mathrm{CG}_{\mathrm{A}}$ and as such it can also be evaluated against the $\mathrm{CG}_{\mathrm{G}}$. This is exemplified in (27): ${ }^{7}$

$$
\begin{aligned}
& \text { A: ha-menahel šel ha-Po'el šilem lido milyon yuro } \\
& \text { The-manager of the-Po'el paid to.me million euros } \\
& \text { 'al eyze falcan } \\
& \text { on some stuck up }
\end{aligned}
$$

'The manager of the ha-Po'el paid one million euros on some stuck up soccer player. That's inappropriate!'

B: ma 'ata roce mimeno?

what you want from.him

ha-menahel šel Makabi lo šilem lexapd milyon yuro

the-manager of Maccabbi not paid to.you million euros

'al eyze falcan?!

on some stuck up

'What do you want from him? The manager of Maccabi didn't pay one million euros on some stuck up soccer player?!'

\footnotetext{
${ }^{7} \mathrm{Ha}-\mathrm{Po}^{\prime} \mathrm{el}$ and Maccabi in this examples are the names of sport groups in Israel.
} 
Discourse update at the service of mirativity effects: The case of the Discursive Dative

A's utterance is no different from (5)/(18). In B's utterance, the DD is felicitous with respect to the answer for the rhetorical question in it (in our case the positive one), which constitutes an exception to the salient generalization.

\section{Concluding remarks}

In this paper we argue that the DD is a discourse management device with the following properties: it is non-truth conditional, it applies to propositions, and it involves only the speech event participants. The current investigation contributes to strengthening the view that our modeling of the CG should be enriched to handle various conversational phenomena. An additional contribution of our paper is to refine the inventory of linguistic expressions, which are crosslinguistically described as having mirativity effects, providing a way to understand their source.

Finally, this type of non-core dative doesn't seem to be unique to Hebrew. The following are examples from French (taken from Leclère 1976), (28), and from the Judeo Arabic of Tafillalt (Bar-Asher Siegal \& Boneh 2015b), (29), two unrelated languages, where a datival expression seems to produce a similar interpretative effect.

(28) Au mont St Michel, la mer te monte à une de ces vitesses ! at Mont St. Michel, the sea to.you rises in one of these speeds 'You won't believe how quickly the sea raises at the Mont St. Michel!'

$\mathbf{C G}_{\mathbf{A}}$ At Mont St. Michel the sea rises very quickly

CGg The sea doesn't usually rise that quick $\vDash$ At Mont St. Michel the sea does not rise very quickly

$\mathrm{CG}_{\mathrm{A}} \not \subset \mathrm{CG}_{\mathbf{G}} \rightarrow \mathrm{DD}$ is felicitous

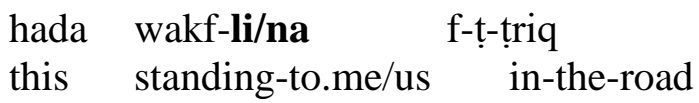

'He's standing in the middle of the road, so weird.'

$\mathbf{C G}_{\mathbf{A}}$ He is standing in the middle of the road

CGG People do not usually stand in the middle of the road $\vDash$ He is not standing in the middle of the road

$\mathrm{CG}_{\mathbf{A}} \not \subset \mathrm{CG}_{\mathbf{G}} \rightarrow \mathrm{DD}$ is felicitous

\section{References}

Ariel, Mira, Elitzur Dattner, John W. Du Bois, and Tal Linzen. 2015. Pronominal datives: The royal road to argument status. Studies in Language 39, 257-321. doi: 10.1075/s1.39.2.01ari 
Discourse update at the service of mirativity effects: The case of the Discursive Dative

Asher, Nicholas \& Michael Moreau 1995. What some generic sentences mean. In Gregory N. Carlson \& Francis J. Pelletier (eds.), The Generic Book, 300-338. Chicago: The University of Chicago Press.

Bar-Asher Siegal, Elitzur \& Boneh, Nora. 2015a. Decomposing affectedness. In Nurit Melnik (ed.) Israel Association for Theoretical Linguistics (IATL) 30. MIT Working Papers in Linguistics.

Bar-Asher Siegal, Elitzur A. \& Nora Boneh. 2015b. Reconsidering the emergence of non-core dative constructions in Modern Hebrew. Journal of Jewish Languages 3, 309-323. doi: 10.1163/9789004310896_024

Berman, Ruth A. 1982. Dative marking of the affectee role: Data from Modern Hebrew. Hebrew Annual Review 6, 35-59.

Borer, Hagit. \& Yosef Grodzinsky. 1986. Syntactic cliticization and lexical cliticization: The case of Hebrew dative clitics. In Hagit Borer (ed.), Syntax and Semantics, 175-217. New York: Academic Press.

Cohen, Ariel. 2004. Existential generics. Linguistics and Philosophy 27, 137-168. doi: 10.1023/B:LING.0000016441.89129.3d

DeLancey, Scott. 1997. Mirativity: The grammatical marking of unexpected information, Linguistic Typology 1, 33-52. doi: 10.1515/lity.1997.1.1.33

DeLancey, Scott. 2001. The mirative and evidentiality. Journal of Pragmatics 33 (3). 369-382. doi:10.1016/S0378-2166(01)80001-1

Farkas, Donka \& Kim Bruce. 2010. On reacting to assertions and polar questions. Journal of Semantics 27(1). 81-118. doi: 10.1093/jos/ffp010

Greenberg, Yael. 2007. Exceptions to generics: Where vagueness, context dependence and modality interact, Journal of Semantics 24, 131-167. doi: $10.1093 /$ jos/ffm002

Gutzmann, Daniel. 2007. Eine Implikatur konventioneller Art: der Dativus Ethicus. Linguistische Berichte no. 211, 277-308.

Juitteau, Mélanie, and Milan Rezac. 2007. The French ethical dative, 13 syntactic tests. Bucharest Working Papers in Linguistics 9, 97-108.

Hamblin, C. L. 1973. Questions in Montague grammar, Foundations of Language 10, 41-53. doi:10.1016/B978-0-12-545850-4.50014-5

Karttunen, Lauri. 1974. Presuppositions and linguistic context, Theoretical Linguistics 1, 181-194.

Karttunen, Lauri. 1977. Syntax and semantics of questions, Linguistics and Philosophy 1, 3-44. doi: 10.1002/9780470758335.ch16

Krifka, Manfred. 2008. Basic notions of information structure. Acta Linguistica Hungarica 55, 243-276. doi: 10.1556/ALing.55.2008.3-4.2

Krifka, Manfred, Francis J. Pelletier, Greg Carlson, Alice ter Meulen, Gennaro Chierchia \& Godehard Link. 1995. Genericity: An introduction. In Gregory N. Carlson \& Francis J. Pelletier (eds.), The Generic Book, 1-124. Chicago: The University of Chicago Press. 
Discourse update at the service of mirativity effects: The case of the Discursive Dative

Leclère, Christian 1976. Datifs syntaxiques et datif éthique. In Jean-Claude Chevalier \& Maurice Gross (eds.), Méthodes en Grammaire française, 7396. Paris: Klincksieck.

Lewis, David. 1979. Scorekeeping in a language game. Journal of Philosophical Logic 8, 339-359. doi: 10.1002/9780470758335.ch6

Michelioudakis, Dimitris \& Eleni Kapogianni. 2013. Ethical Datives: A puzzle for syntax, semantics, pragmatics, and their interfaces. In Folli Raffaella, Christina Sevdali \& Robert Truswell (eds.), Syntax and its limits. Oxford Studies in Theoretical Linguistics, 345-369. Oxford: Oxford University Press.

Murray, Sarah. E. 2014. Varieties of update. Semantics and Pragmatics 7(2). 153. doi: $10.3765 /$ sp.7.2

Peterson, Tyler. 2013. Rethinking mirativity: The expression and implication of surprise.

http://semanticsarchive.net/Archive/2FkYTg4O/Rethinking_Mirativity.pdf

Portner, Paul. 2004. The semantics of imperatives within a theory of clause types. In Robert B. Young (ed.), Semantics and Linguistic Theory (SALT) 14, 235252. doi: http://dx.doi.org/10.3765/salt.v14i0.2907.

Portner, Paul. 2007. Beyond the CG: The semantics and pragmatics of epistemic modals. Talk. International Conference on Linguistics in Korea.

Rákosi, György. 2008. Some remarks on Hungarian ethical datives. In Béla Hollósy József Andor, Tibor Laczkó, \& Péter Pelyvás (eds.), When grammar minds language and literature. Festchrift for Prof. Béla Korponay on the occasion of his 80th birthday, 413-422. Debrecen: Institute of English and American Studies, University of Debrecen.

Repp, Sophie. 2013. Common Ground management: Modal particles, illocutionary negation and VERUM. In Daniel Gutzmann \& Hans-Martin Gärtner (eds.), Beyond Expressives - Explorations in Use-conditional Meaning, 231-274. Leiden, Boston: Emerald. CRISPI Series.

Rett, Jessica. 2009. A degree account of exclamatives. In Tova Friedman \& Satoshi Ito (eds.), Semantics and Linguistic Theory (SALT) 18, 601-618.

Rett, Jessica and Sarah Murray. 2013. A semantic account of mirative evidentials. In Todd Snider (ed.), Semantics and Linguistic Theory (SALT) 23, 453-472. doi: http://dx.doi.org/10.3765/salt.v18i0.2470

Romero, Maribel and Cung-Hye Han, 2004. On negative yes/no questions. Linguistics and Philosophy 27, 609-658.

doi: 10.1023/B:LING.0000033850.15705.94

Rooryck, Johan. 2001. Evidentiality, Part I, Glot International 5(4). 125-133. Oxford: Blackwell Publishers.

Stalnaker, Robert. 1978. Assertion. In Peter Cole (ed.), Pragmatics, 215-323. New York: Academic Press. 
Discourse update at the service of mirativity effects: The case of the Discursive Dative

Elitzur Bar-Asher Siegal

The Hebrew University of Jerusalem

Mount Scopus 9190501

Jerusalem, Israel

ebas@mail.huji.ac.il
Nora Boneh

The Hebrew University of Jerusalem

Mount Scopus 9190501

Jerusalem, Israel

nora.boneh@mail.huji.ac.il 